\title{
Recovery of combustible matter from waste fine Chinese coals by a waste vegetable oil agglomerating process and its combustion characteristics
}

\author{
Q. Wang, N. Kashiwagi, P. Apaer, Q. Chen, Y. Wang, \\ T. Maezono \& D. Niida \\ Department of Environmental Science and Technology, \\ Graduate School of Science and Engineering, Saitama University, Japan
}

\begin{abstract}
Coal production increases continuously due to the development of mechanization in coal mining and demand in its related fields of application worldwide. Especially, coal production in China is increasing and a large amount of waste fine coals $(<0.5 \mathrm{~mm})$ which are difficult to be cleaned. Waste fine coals usually contain large amounts of ash contents and inorganic sulfur contents due to the mechanical coal mining of low grade coals. Therefore, waste fine coals are unavailable as energy resources, spontaneous combustion leading in turn to air pollution because of their coal content and small size which increases the surface area liable to be wet and oxidized, and occupation of disposal land which is also lead soil and water contamination.

In this study, a waste vegetable oil agglomerating process was approached for coal combustible matter recovery from Chongqing Nantong waste fine coals in China. The oil agglomerating process had usually been developed by mineral oil (such as kerosene) of exhaustible resource. Therefore, in this study, simulated waste vegetable oils are selected as oil agglutinative agents because the waste vegetable oils which are recycled, renewable, and less polluting energy resources from the point of view of effective utilization of waste coal and on the cost front. However, waste vegetable oils have the possibility of influence on the coal cleaning efficiency, because the waste vegetable oils may be changed in the surface property and viscosity by different kinds of vegetable oils and chemical structure with the usage environment. Therefore, in the study, cleaning coal
\end{abstract}


efficiency of oil agglomeration was investigated when simulated waste vegetable oil (heating of colza oil) was used as an agglutinative agent. The effects of parameters including the viscosity and chemical structure were investigated based on the combustible matter recovery, ash reduction and efficiency index. Furthermore, combustion characteristics of combustible matter were determined with ignition temperature and burning behavior by TG-DTA. It can be concluded that the viscosity, types of vegetable oils, heating time and frying time of waste vegetable oils with the usage environment will influence the coal cleaning efficiency.

Keywords: waste fine coal, waste vegetable oil, renewable energy, oil agglomerating process, China.

\section{Introduction}

The primary energy consumption expands, because it is thought to be an increase in the future by improving the living standard in the world [1]. The recoverable coal reserves are estimated that about 847.5 billion tons [2] and the reserveproduction ratios of coal are 133 years [2]. It is thought that coal will be important energy because it is excellent in the stability of supply and the economy than other fossil fuels, because there is no eccentrically-located. However, large amount of waste fine coal $(<500 \mu \mathrm{m})$ is produced by mechanizing the coal preparation process and mining. Because of the pulverized coal with the small particle sizes in diameter, the handling of waste fine coals is difficult, which contained a lot of minerals and the calorific value is low [3, 4]. The utility value as an energy resource is scarce, thus the a lot waste fine coals have been discarding. However, combustible matter is still contained in waste fine coals, it is discards risk of spontaneous combustion, additionally it causes land occupation, air pollution, and water pollution and land occupation. Especially in China, waste fine coal of production has grown in quantity and this problem has become aggravated. Then, it is needed coal clean technology in order that recovery of combustible matter from waste fine coals for reduction of environmental burdens and application of unused resources.

Oil agglomeration in wet processes has been also found to be one approach of the effective methods for separating the combustible matter (organic and carbonaceous contents) from mineral matter (ash contents) of waste fine coals. The oil agglomerating process apply the different surface properties of combustible organic matter and mineral matter in raw coals to coal cleaning technique, separation of coal from mineral matter is achieved due to differences in the surface hydrophobic properties of the organic coal and inorganic ash contents of coal samples. The principle of a vegetable oil agglomerating process is shown in figure 1 .

In the past, mineral oil (kerosene) from exhaustible resource has used oil agglomeration. However, the vegetable oils have been selected as oil agglutinative agents in our previous study [5] because the vegetable oils which are renewable, available and less-polluting energy resources. Furthermore, in this 


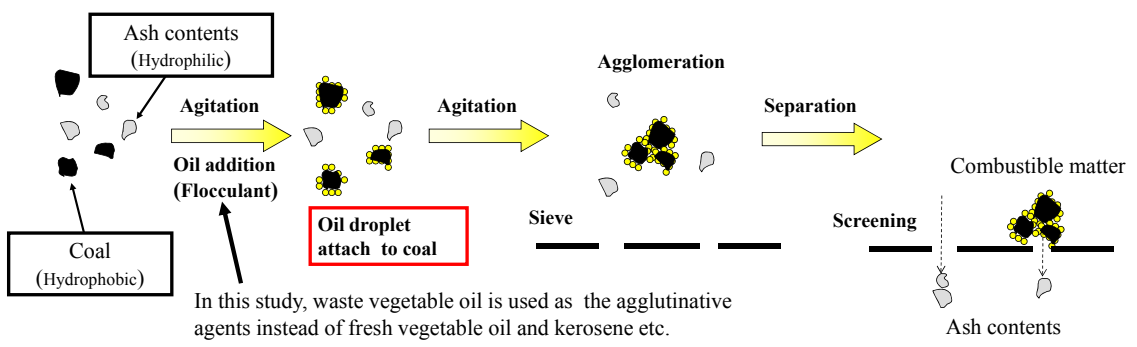

Figure 1: Principle and concept of a vegetable oil agglomerating process for waste fine coal cleaning.

study, we try to use the waste vegetable oils such as colza oil as the agglutinative agents instead of their original fresh vegetable oils.

However, waste vegetable oils have the possibility of influence on the coal cleaning efficiency, because the waste vegetable oils may be changed in the surface property and viscosity by different kinds of vegetable oils and chemical structure with the usage environment. Especially, in the food processing, vegetable oils are heated at about $180{ }^{\circ} \mathrm{C}$, as the results, polar molecules could be produced from the degraded products of its original vegetable oil. Therefore, these products may be show different agglomeration behavior since agglutinative agents between ash particles and oil droplets which possibly show a hydrophilic behavior and probably induce some effects on oil agglomeration.

The main object of this work is to recovery of combustible matter more efficiency by a waste vegetable oil agglomeration, thus chemical structure and property of vegetable oil, thus, a wide range of oil alteration grades and therefore, of oil properties, such as viscosity and unsaturated carbonaceous bonds by the oxidation processes in the used waste vegetable oils were investigated. Structural changes and unsaturated carbonaceous functional groups in the colza oils were monitored by a Fourier-transform infrared (FTIR) method. Oil agglomeration efficiency was evaluated by measuring the recovery of combustible matter, ash reduction and efficiency index. Furthermore, combustion characteristics of combustible matter were determined with ignition temperature and burning behavior by TG-DTA.

\section{Materials and experimental methods}

\subsection{Waste fine coal samples}

In this study, the samples of waste fine coals were selected and collected from Chongqing Nantong coal mining in the south-eastern China. Before our experiments, the coal samples were prepared below a $75 \mu \mathrm{m}$ by sieve. The proximate and ultimate analyses of coal samples were measurement according to the Japanese industrial standard (JIS) method of JIS-M8812. 


\subsection{Experiment of oil agglomeration for waste fine coal cleaning}

Schematic diagram of a procedure of oil agglomeration is given in figure 2, and experimental conditions are shown in table 1 . The oil agglomeration experiments were carried out in a $500 \mathrm{~mL}$ beaker. The products of the two simultaneous agglomeration experiments were poured into the beaker and mixed, followed by the separation of the agglomerates as clean coals. The agglomerates were filtered, dried overnight at the room temperature, washed with ethanol and diethyl ether to extract the residual oil, dried at room temperature, and analyzed for ash content in each clean coal. As the results, the resultant agglomeration products were separated from the mineral matter (ash) in waste fine coals below $75 \mu \mathrm{m}$. Actually, on the industrial application, we should say that the solvent washing step of the agglomerates would not be necessary and the coal/waste vegetable oil agglomerates could be used directly as fuel because of the lesspollutants in the waste vegetable oils.

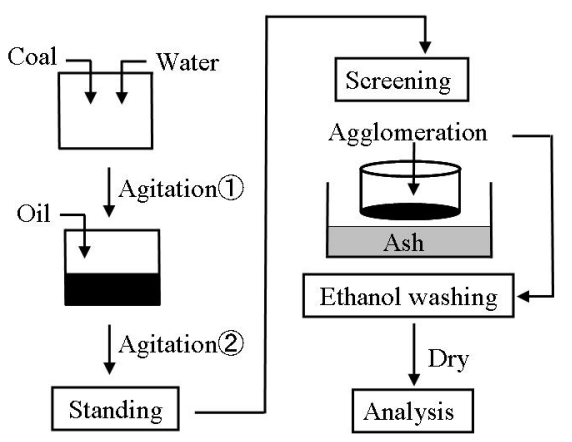

Figure 2: Schematic diagram of coal cleaning procedure of oil agglomeration.

Table 1: $\quad$ Experimental conditions of oil agglomeration.

\begin{tabular}{l|l}
\hline Item & Condition \\
\hline Coal & $15.0 \mathrm{~g}$ \\
Particle size & $<75 \mu \mathrm{m}$ \\
Water & $200 \mathrm{~mL}$ \\
Oil concentration & $4.0 \mathrm{~g}$ \\
Agitation (1) & Time: $2 \mathrm{~min}$, Speed: $2000 \mathrm{rpm}$ \\
Agitation (2) & Time: $5 \mathrm{~min}$, Speed: $2000 \mathrm{rpm}$ \\
Standing time & $3 \mathrm{~min}$ \\
\hline
\end{tabular}




\subsection{Preparation of waste vegetable oil samples}

\subsubsection{Preparation of the simulated waste vegetable oil samples}

With a point of view for effective utilization of waste vegetable oil, it was necessary to use waste vegetable oil in the experiment of oil agglomeration. Therefore, it is necessary to prepare different waste vegetable oils when viscosity and chemical structures changed with the different cooking time and conditions.

In the case of heated-treated oil, carbonyl compound and carboxylic acid degraded products of oils may be advanced. These products are hydrophilic behavior, as the results, there may be an adverse effect for efficiency of clean coal during the oil agglomerating process, because these products are effective like cross-linker between combustible matter and ash contents.

Therefore, for preparing the waste vegetable oils, a commercial colza sample oil was poured into metallic pot about $1.0 \mathrm{~L}$ and heated at $180^{\circ} \mathrm{C}$ for $24 \mathrm{~h}$ by an electric hot plate during 5 days heating experiment period. The simulated waste vegetable oil samples in different heated-treated days were used as the coal agglomerating agents in this work to check the availableness and capability of the waste vegetable oil agglomeration. The simulated waste colza oil samples heated each day was cooled at the room temperature and restored till experiments of oil agglomeration.

\subsection{Identification for chemical structure change in simulated waste colza oil samples by a FT-IR}

In order to find changes in chemical structure of waste vegetable oil samples mentioned in section 2.3 based on the Fourier-transform infrared (FTIR) technology, the infrared spectra were recorded using a Model IR-6100 (JASCO Corporation, Japan) interfaced to a personal computer operating with Windowsbased Spectra manager (Version 2). A film of the oil sample was placed between two disks of $\mathrm{NaCl}$. This study is used disk path length of $\mathrm{NaCl}$ cells of $0.1 \mathrm{~mm}$. The spectra were recorded from $4000 \mathrm{~cm}^{-1}$ to $400 \mathrm{~cm}^{-1}$, the number of scans being 256 at a resolution of $4 \mathrm{~cm}^{-1}$. A simulated waste vegetable oil diluted with $\mathrm{CCl}_{4}$ by $1 / 100 \mathrm{M}$.

\subsection{Measurement of the colza oil viscosity}

A viscometer (Model VT-04F, RION Co. Ltd., Japan) was used to measure the viscosity of the oils. In this procedure, a disk/spindle is submerged in the oil and the force which is necessary to overcome the resistance of the viscosity to the rotation is measured. The viscosity value (dPas) of the testing solution is automatically calculated on the basis of the speed and the geometry of the spindle. According to previous vegetable oil viscosity values which were determined basing on the Japanese industrial standard (JIS) method of JISZ8803, a spindle speed of $62.5 \mathrm{rpm}$ was chosen in this work to carry out the measurements. 


\subsection{Evaluation of coal cleaning efficiencies by the waste vegetable oil agglomerating process}

The efficiencies of coal cleaning were calculated by the mass percentages ( $\mathrm{wt} \%$ ) of combustible matter recovery (CMR), ash reduction (AR) and efficiency index (EI) from ash content in clean coal [6]. These parameters can be calculated as the following equations (1)-(3).

$$
\begin{gathered}
\mathrm{CMR}=100 \times \frac{\mathrm{CM}_{\text {agglom }}(\mathrm{wt} \%) \times \mathrm{wt}_{\text {agglom }}(\mathrm{g})}{\mathrm{CM} \mathrm{M}_{\text {feed }}(\mathrm{wt} \%) \times \mathrm{wt}_{\text {feed }}(\mathrm{g})} \\
\mathrm{AR}=100 \times\left[1-\frac{\mathrm{Ash}_{\text {agglom }}(\mathrm{wt} \%) \times \mathrm{Ash}_{\text {agglom }}(\mathrm{g})}{\mathrm{CM} \mathrm{M}_{\text {feed }}(\mathrm{wt} \%) \times \mathrm{wt}_{\text {feed }}(\mathrm{g})}\right] \\
\mathrm{EI}=\mathrm{CMR}+\mathrm{AR}
\end{gathered}
$$

Here, CM (combustible matter) is calculated as 100-(ash contents), agglom is the weight of agglomeration, feed is the weight of coal samples, and wt gives as the weight unit $(\mathrm{g})$, respectively.

\subsection{Evaluation of combustion characteristics of combustible matter}

The thermogravimetric/differential thermal analysis (TG/DTA) measured combustion characteristics of recovery combustible matter which is ignition temperature and behavior. In all the experiments, 3.5-4.0 $\mathrm{mg}$ of sample were heated at $15{ }^{\circ} \mathrm{C} / \mathrm{min}$ from room temperature to $750{ }^{\circ} \mathrm{C}$. A gas flow rate of 50 $60 \mathrm{~mL} / \mathrm{min}$ was used; clean gas used as the carrier gas for combustion. The combustion characteristics of oil agglomerates which were not washed by solvent, waste fine coal and standard coal were measured, respectively.

\section{Results and discussions}

\subsection{Changing tendency in viscosity of the simulated waste vegetable oils}

The changing tendency in the viscosity of waste vegetable oils when the heating time changed shown in figure 3. The viscosity of simulated waste colza oil was greatly increased with heating time after 3 days. This is due to increment of viscosity with the oxidized compound formation of oxygen-containing group and polymerization of triglyceride.

\subsection{Effect of viscosity on the performance of CMR and AR}

CMR and AR was investigated effect of changed viscosity of waste vegetable oil. The results of proximate and ultimate analysis of used waste fine coal for experiment are shown in table 2. 


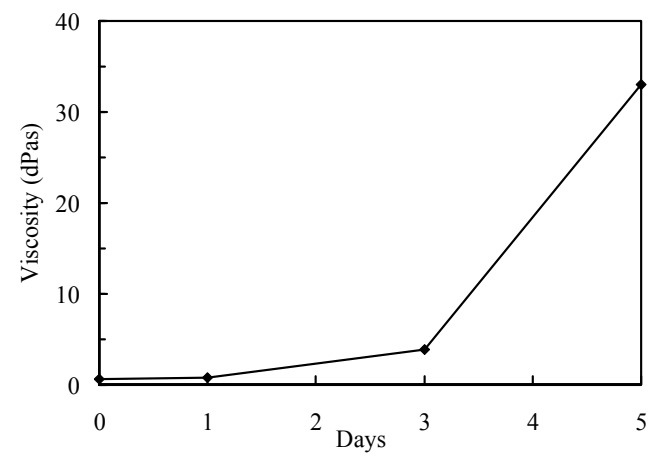

Figure 3: $\quad$ Viscosity of simulated waste colza oil.

Table 2: $\quad$ Results of proximate analysis and ultimate analysis (coal particle sizes: $<75 \mu \mathrm{m})$.

\begin{tabular}{ccccccccccc}
\hline & \multirow{2}{*}{ Particle size $(\mu \mathrm{m})$} & \multicolumn{4}{c}{ Proximate analysis $(\mathrm{wt} \%)$} & \multicolumn{4}{c}{ Ultimate analysis (\%) } \\
\cline { 2 - 11 } & & Ash & Water & VM & FC & C & H & N & S & O \\
\hline Waste coal & $<75$ & 61.3 & 2.9 & 18.3 & 17.8 & 18.1 & 1.7 & 0.4 & 9.6 & 7.0 \\
\hline
\end{tabular}

VM: Volatile matter, FC: Fixed carbon

Figure 4 shows that effect of viscosity on oil agglomeration performance. As can be seen, when the viscosity of waste vegetable oil increased, CMR was increased and most high value at $3.9 \mathrm{dPas}$. However, an excessive increase in viscosity was drastically decreased CMR. Because of tack strength was increased by more intense intermolecular force, CMR was high value. But, waste vegetable oil for excessive increased viscosity cannot be scattered in a suspension because CMR was drastically decreased. Therefore, if viscosity of waste vegetable oil is too high value, oil agglomeration cannot be performed.

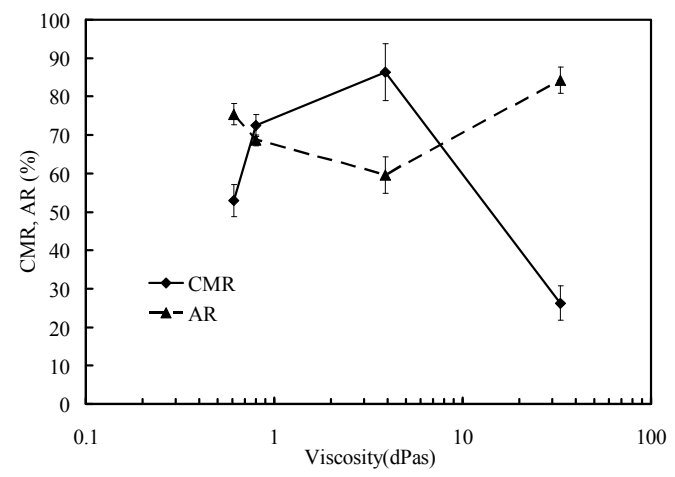

Figure 4: $\quad$ Effect of viscosity on the performance of CMR and AR. 
On the other hand, AR value was decreased when waste vegetable oil was increased. Because of polar molecular was formed, constitutive part of vegetable oil of molecular changed micelle. Therefore, micelle showed the effect of crosslinking agent upon ash.

\subsection{Effect of viscosity on the performance of EI}

The effect for oil agglomeration performance due to changing in the viscosity of the simulated waste vegetable oils was given in figure 5. The highest EI value with the best oil agglomeration performance by the simulated waste vegetable oil was at $3.9 \mathrm{dPas}$, in contrast, poor oil agglomeration performance with the lowest EI value was at $30 \mathrm{dPas}$ of the viscosity. For this reason, it is possible that waste vegetable oils can be applicable to oil agglomerating process. However, the oil agglomeration performance seems to be influenced by the quality (viscosity) of waste vegetable oils. It is thought that it is unfavorable to use waste vegetable oil more than $4 \mathrm{dPas}$ in its viscosity because it became inefficient.

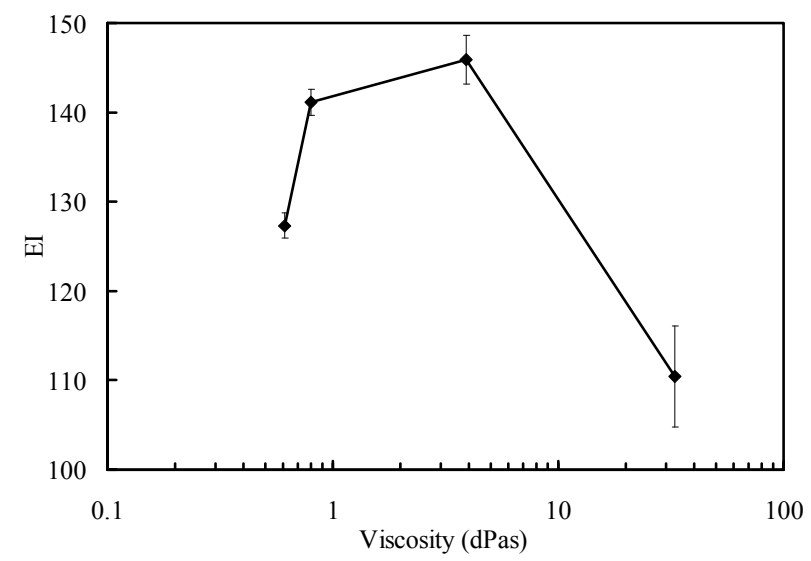

Figure 5: $\quad$ Effect of viscosity on the performance of EI.

\subsection{Some chemical structures influenced on oil agglomeration}

The FTIR technology has been commonly used for the structural identification or qualitative determination of the fingerprint of organic compounds, because some groups of atoms display the specific characteristic vibrational absorption frequencies in this infrared region of the electromagnetic spectrum [7]. Spectra in the mid-infrared region have well resolved bands that can be assigned to functional groups of the components of the oil samples. The exact location of the corresponding bands depends on the influence of the rest of the molecule. The infrared absorption frequencies characteristic of functional groups afford a useful and valuable tool for the chemical structural elucidation of waste vegetable oil was investigated by a FT-IR. The analytical evaluation of the colza oil spectra is given in table 3 [8]. 
The spectra of oil samples stretching vibration of the $\mathrm{CH}$ stretching vibration of the cis-double bond and ester carbonyl functional group of the triglycerides shown in figure 6 and figure 7. In the heating experiments, colza oil was heated for 5 days at $180{ }^{\circ} \mathrm{C}$ and the changes in the FT-IR spectra were observed. As can be seen in figure 6 , this absorbance of spectra bands at 2928 and $2856 \mathrm{~cm}^{-1}$ and the shoulders at $2962 \mathrm{~cm}^{-1}$ increase their intensity, but the bands at $3008 \mathrm{~cm}^{-1}$ decreased absorbance. Increment of the heating time may induce to increase the band width of absorbance. A shoulder at $2872 \mathrm{~cm}^{-1}$ is also formed attributed to the production of $\mathrm{CH}_{3}$ groups, on another front, figure 7 shown that the band at $1725 \mathrm{~cm}^{-1}$ present aldehyde and other secondary oxidation compounds (e.g. ketone) with which the maximum absorbance of aldehyde is at $1725 \mathrm{~cm}^{-1}$ and that of ketone is $1715 \mathrm{~cm}^{-1}$ in the spectra.

Table 3: Functional groups and modes of vibration in the FT-IR of oil.

\begin{tabular}{ll}
\hline Frequency $\left(\mathrm{cm}^{-1}\right)$ & Functional group assignment \\
\hline 3008 & CH stretching vibration of the cis-double bond $(=\mathrm{C}-\mathrm{H})$ \\
2928 and 2856 & $\begin{array}{l}\text { Symmetric and asymmetric stretching vibration of the aliphatic } \\
\mathrm{CH}_{2} \text { group }\end{array}$ \\
2962,2872 & $\begin{array}{l}\text { Symmetric and asymmetric stretching vibration shoulder of the } \\
\text { aliphatic } \mathrm{CH}_{3} \text { group }\end{array}$ \\
1746 & $\begin{array}{l}\text { Ester carbonyl functional group of the triglycerides } \\
1711\end{array}$ \\
\hline
\end{tabular}

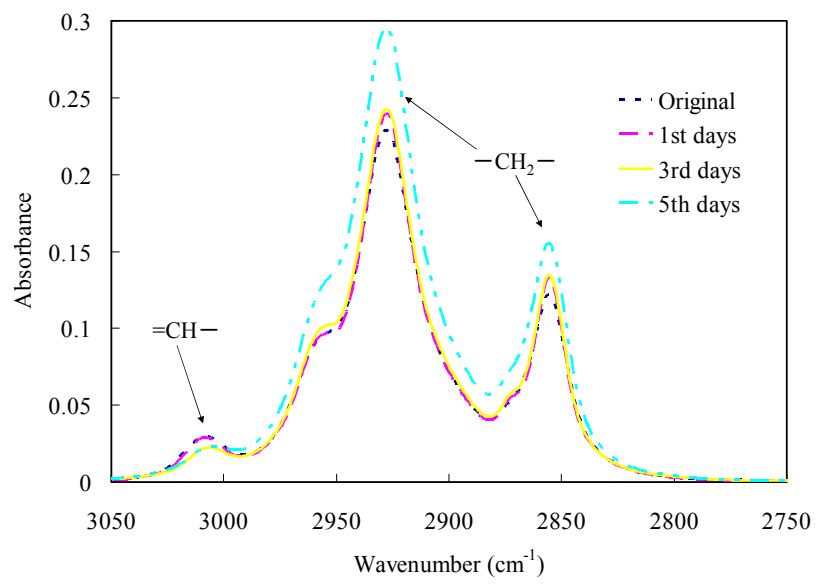

Figure 6: $\quad$ FT-IR spectra $\left(3050-2750 \mathrm{~cm}^{-1}\right)$ of oil samples heated at $180^{\circ} \mathrm{C}$ for 0-5 days after. 


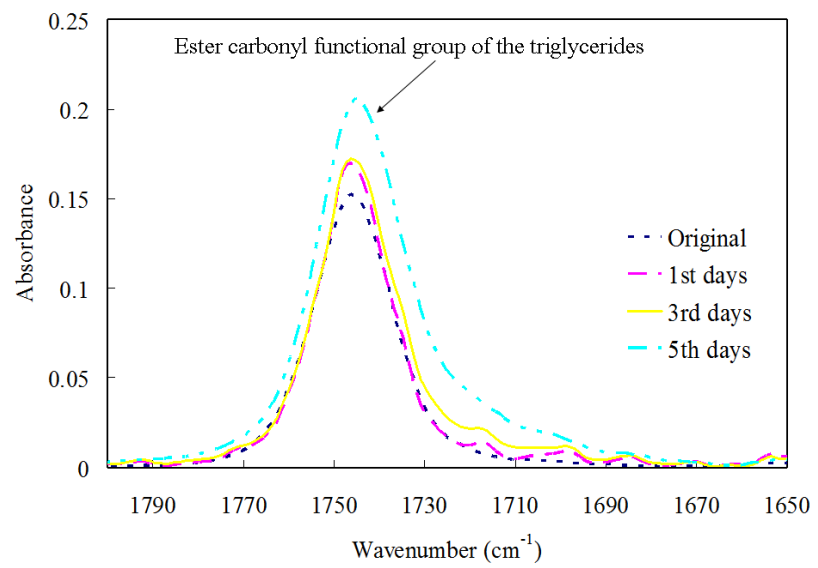

Figure 7: $\quad$ FT-IR spectra $\left(1800-1650 \mathrm{~cm}^{-1}\right)$ of oil samples heated at $180^{\circ} \mathrm{C}$ for 0-5 days after.

\subsection{Investigation of combustible characteristics by a TG-DTA}

The evaluation of combustion characteristics of waste fine coal, aggregate (original fresh colza oil and heated oils for 3 days) and standard coal were investigated with the analysis of the TG/DTA. As it has been seen in figure 8 , the temperature range from the beginning of the tests up to the ignition temperature can determine the initial heating, release of volatile matters and combustion behavior. At the ignition points of each coal samples, a sharp exothermic peak is observed due to the combustion process. The each coal presents the first endothermic peak at around $100^{\circ} \mathrm{C}$ due to the loss of moisture [9].

For waste fine coal and clean coal by the original fresh colza oil agglomeration, different peaks can be determined by the TG/DTA. The ignition temperature of standard coal was around $520{ }^{\circ} \mathrm{C}$ whereas lower ignition temperature of clean coals by colza oil agglomeration. And ignition temperature of its clean coal was lower than standard coal (c) about $50{ }^{\circ} \mathrm{C}$. The clean coal of original oil (b) presented some peak which may be due to vegetable oil and waste coal (d) separately burned. On the other hand, it can be coinstantaneously burned for clean coal by colza oil agglomeration of which the oil has been heated for 3 days after (a).

These results show that it is possible that waste vegetable oil agglomeration can be better combustion characteristics than its original coal. As mentioned in section 3.3 before, since the highest EI value with the best oil agglomeration performance by the simulated waste vegetable oil was at $3.9 \mathrm{dPas}$, it was improved combustible characteristics of recovery from its original waste fine coals. If we can select the optimized conditions for waste colza oil agglomerating process, the waste vegetable oil could be applied on the industrial oil agglomerating process of Chinese waste fine coals. 

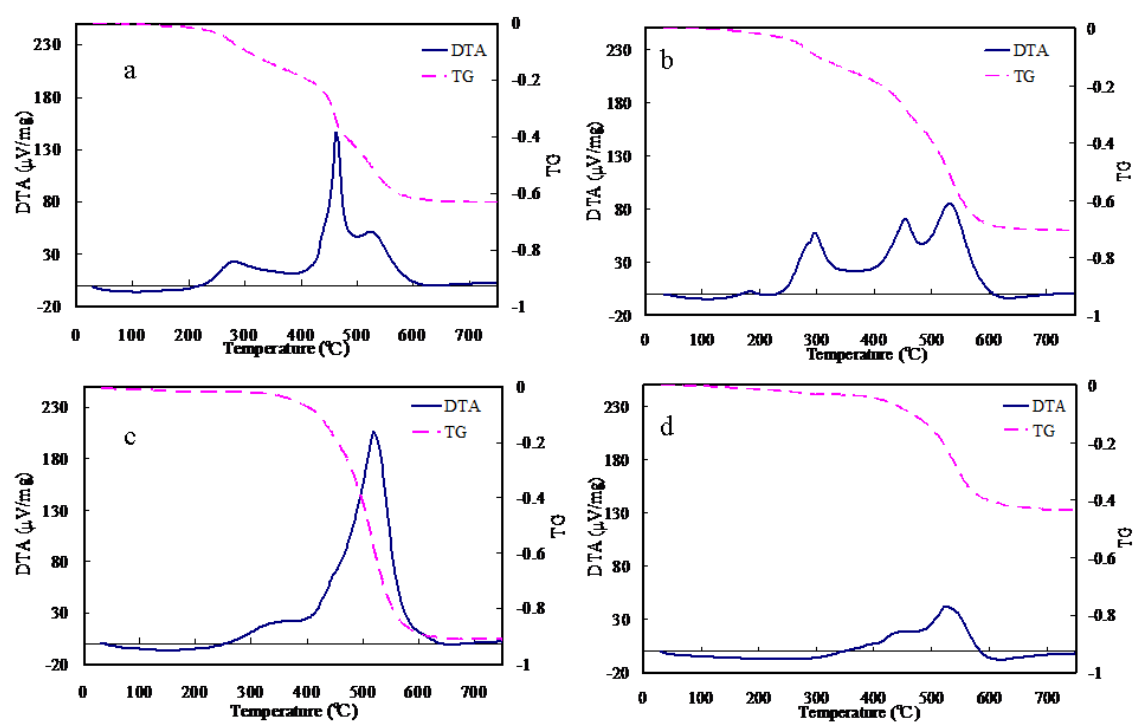

Figure 8: Combustion characteristics of different coal samples after or before the oil agglomerating processes: a) clean coal by oil agglomeration with heated colza oil for 3 days, b) clean coal by the original fresh colza oil agglomeration, c) standard coal and d) original waste fine coal.

\section{Conclusion}

In this study, waste vegetable oil was prepared to investigate affect of efficiency oil agglomeration and combustible characteristics for coal combustible matter recovery from Chongqing Nantong waste fine coals in China. The simulated waste vegetable oil was prepared by commercial colza sample oil. It is possible that the waste vegetable oil seems to be influence on the coal cleaning efficiency, because the waste vegetable oils may be changed in the surface property and viscosity by different kinds of vegetable oils. It was found that the chemical structure of the vegetable oil is changed with ester carbonyl functional group of the triglycerides and secondary oxidation compounds (e.g. ketone) by the analysis of FT-IR.

With the help of waste vegetable oil agglomeration, it was improved combustible characteristics of recovery from its original waste fine coals. These conditions needed optimization in order that efficiently oil agglomeration technology conducted. From the results of our study, the waste vegetable oil can be applied on the industrial oil agglomerating process. Therefore, there are the future subjects that a wide variety of waste vegetable oils are used on our further applicable experiments for Chinese waste fine coal cleaning. 


\section{Acknowledgement}

Some works of this study were supported by the Special Funds for Basic Research (B) (No. 19404021, FY2007 FY2009 and No. 22404022, FY2010 2012) of Grant-in-Aid for Scientific Research of the Japanese Ministry of Education, Culture, Sports, Science and Technology (MEXT), Japan.

\section{References}

[1] World Energy Outlook 2007 - China's Energy Prospects, ISBN: 978-92-6402730-5, IEA.

[2] Agency for Natural Resources and Energy, annual report about energy 139144, 2009 (in Japanese).

[3] M. I. Alonso., A. F. Valdés., R. M. Martínez-Tarazona., A. B. Garcia., Coal recovery from fines cleaning wastes by agglomeration with colza oil: a contribution to the environment and energy preservation, Fuel Processing Technology, 75, 85-95, 2002.

[4] Adolfo F. Valdes., Ana B. Garcia., On the utilization of waste vegetable oils (WVO) as agglomerants to recover coal from coal fines cleaning waste (CFCW), Fuel, 85, 607-614, 2006.

[5] Q. Wang, N. Kashiwagi, P. Apaer, Q. Chen, Y. Wang and T. Maezono, Study on coal recovery technology from waste fine Chinese coals by a vegetable oil agglomeration process, The Sustainable World, Ecology and the Environment, 142, 331-342, 2010.

[6] A. B. Garcia. M. Rosa Martinez-Tarazona., Jose M. G. Vega., Cleaning of Spanish high-rank coals by agglomeration with vegetable oils, Fuel, 75, 885-890, 1996.

[7] Maria D. Guillen., Nerea Cabo., Infrared Spectroscopy in the Study of Edible Oils and Fats, J. Sci Food Agric, 75, 1-11, 1997.

[8] N. Vlachos, Y. Skopelitis, M. Psaroudaki, V. Konstantinidou, A. Chatzilazarou, E. Tegou, Applications of Fourier transform-infrared spectroscopy to edible oils, Analytica Chimica Acta 573-574, 459-465 2006.

[9] A. Arenillas, F. Rubiera, B. Arias, J. J. Pis, J. M. Faúndez, A. L. Gordon and X. A. García, A TG/DTA study on the effect of coal blending on ignition behaviour, Journal of Thermal Analysis and Calorimetry, 76, 603-614, 2004. 